\title{
Fretting-Wear Mechanism of Textured Surfaces
}

\author{
Mykhailo Pashechko' ${ }^{1}$, Volodymyr Marchuk², Myroslav Kindrachuk², \\ Oleksandr Tisov ${ }^{2}$, Anatolii Kornienko' ${ }^{2}$, Oleksandr Dukhota ${ }^{2}$ \\ 1 Department of Fundamentals of Technology, Lublin University of Technology, Poland \\ 2 Engineering Department, National Aviation University, Kyiv, Ukraine \\ * Corresponding author's e-mail: mpashechko@hotmail.com
}

\begin{abstract}
The wear mechanism of textured dimpled in conditions of lubricated fretting-wear is established, which, in contrast to others, takes into account possibility of removing deterioration products out of tribo-contact areas into dimples, preventing their action as abrasive material. Selection of optimal structural parameters of selectively dimpled areas allows to reduce duration of tribological couple running-in time. Depending on texture type, friction coefficient was reduced from 0.27 (for untreated furface) to 0.18 , and wear loss - from $7.8 \times 10^{-3} \mathrm{~g}$ to $3.3 \times 10^{-3} \mathrm{~g}$.
\end{abstract}

Keywords: wear mechanism, fretting, wear products, textured surface, dimple

\section{INTRODUCTION}

High wear resistance and durability of machine elements is defined by strength and wear resistance of contacting surfaces, and fretting-wear is a special form of their destruction. Frettingwear occurs in tribological couples in the presence of vibrations, which cause cyclic microdisplacements of contiguous surfaces. The cycling nature of fretting also leads to decrease in fatigue strength of contacting surfaces, developing fatigue fracture. The mechanism of wear in such conditions is caused by multiple factors. Actually it is quite hard to study fretting-wear and to select countermeasures [1-3].

One of the promising solutions that can solve the problems of reliability and durability of mechanisms in extreme conditions of operation, as well as create the necessary conditions for lubrication with boundary friction is the use of textured surfaces [4-6]. Authors here [7] use textured surfaces to improve lubrication of steel surface by GaIn LM lubricant. Lubrication regime in identical conditions for textured and untextured surfaces appeard to be dissimilar. The application of composite texture even improves noise performance of journal bearings [8]. Other authors pay attention to electrodynamic prosesses and concider contact of microasperities (depending on type) as contact of metal-semicinductor or two dissimilar semiconductors [9]. Textured surfaces may be produced by variety of methods. Depending on materials and further product application, it may be laser peenning [10], micro and nano laser texturing [11-13] electrodischarge mashinning [14] or micromachinning methods [15].

The mechanism of wear of textured surfaces in conditions of boundary friction is sophisticated and depends on many factors [15-16]. The process of friction and wear of textured surfaces occur on the actual area of contact. In paper [17] The reason of lubrication of textured surfaces was considered and discussed, but that was not done for fretting conditions. Also, the review of manufacturing methods was done. The main role of textured areas on the surface is to supply the lubricant to the contact area in order to restore the lubricating action of the lubricant boundary film after its destruction [18]. The rate of restoration of the lubricanting film depends on the mechanism of supplying the lubricant to 
the places of tribocontact, diffusion, surface lubrication and spreading of liquid lubricant. The mechanism of wear in such conditions is multifaceted, and in real conditions this leads to difficulties in studying and choosing the means to counteract the wear [19].

Among many methods of protection against fretting, the most simple and effective in terms of practical implementation is a mechanical method - formation of selectively treated surfaces (textured dimpled surfaces). Dimples are produced by dynamic action of indenter on surface by means of material plastic deformation. Choosing the optimal layout of dimples allows to construct a surface with high operational properties, improved tribotechnical characteristics and controlled stress-strained state of the surface [20-21]. Figuring-out the mechanism of fretting-wear of textured surfaces and based on this finding means to control these processes - is an objectives of the study [22]. So, the purpose of the work is to study the fretning-wear process of textured surfaces in conditions of boundary friction and to detect the mechanism of their wear depending on geometry (type and distribution over the surface) of texture.

\section{MATERIALS AND RESEARCH METHODS}

Fretting-wear tests were carried out using MFK-1 test rig. Specimens were manufactured in accordance with GOST 23.211-80. Parameters of test: specific load $-P=20 \mathrm{MPa}$; amplitude of specimen's relative displacement $-A=175 \mu \mathrm{m}$; frequency of oscillations $-f$ $=25 \mathrm{~Hz}$; Test duration $-N=10^{5}$ cycles. The design and operation of MFK-1 test rig is described in [18]. In the course of the tests, linear wear and friction coefficient were measured depending on number of fretting cycles.
For the production of specimens, on the surface of which dimples were formed, steel 30HGSA (0.3C-Cr-Mn-Si with reduced content of sulfur and phosphorus) was used (in supply condition) without any additional heat treatment. This was done from point of view to provide the most adverse material conditions (in terms of hardness, intrinsic wear resistance), and how in this conditions surface texturing will influence wear resistance of specimens. As a counterpart material steel 45 (analog of AISI 1045), quenched and tempered with hardness of HRC 52-54 was used.

The working surface of specimens and counterparts was grinded to $\mathrm{Ra}=0.32 \mu \mathrm{m}$. Dimples were formed on a flat end surface of the specimens by plastic deformation of material as a result of indenter impacts with the help of device described in [23], which allows adjustment, depending on indenter head motion, depth of dimples, as well as in-row distance between dimples and distance between rows.

Two batches of specimens with dissimilar parameters of surface texture were prepared. Texture geometry is specified in Table 1 .

\section{RESULTS AND DISCUSSION}

Experimental studies of textured specimens under friting conditions are presented in Table 2. As a result of the study, it was found that initial material, without texture is most severely deteriorated.

The peculiarity of wear of original untextured specimens is due to the fact that, as a result of strengthening asperities on actual contact points and their destruction, primary products of deterioration, some of which are oxidized, are formed. In subsurface layers, fatigue phenomena are progressing, which are accompanied by competing processes of strengthening and fracture. As a

Table 1. Test specimens texture parameters

\begin{tabular}{|c|c|c|c|}
\hline No. & Distance between rows, $m$ & In-row distance, $m$ & Depth of dimples, $m$ \\
\hline Texture 1 & $2.0 \times 10^{-3}$ & $2.0 \times 10^{-3}$ & $1.0 \times 10^{-3}$ \\
\hline Texture 2 & $2.0 \times 10^{-3}$ & $2.0 \times 10^{-3}$ & $1.5 \times 10^{-3}$ \\
\hline
\end{tabular}

Table 2. Results of tribological tests

\begin{tabular}{|c|c|c|c|}
\hline No. & Specimen treatment & Friction coefficient & Weight loss, $g$. \\
\hline 1 & No texture & 0.27 & 0.0078 \\
\hline 2 & Texture 1 & 0.2 & 0.0043 \\
\hline 3 & Texture 2 & 0.18 & 0.0033 \\
\hline
\end{tabular}


result of this fatigue microcracks appear (Fig. 1a). Separate abrasive particles are impressed into the friction surface. This leads to redistribution of pressure on contact areas. As a result, the middle section of contact area is subjected to more severe wear than peripheral areas. This causes appearance of recesses on the surface. The fractions of wear products fill the adjacent recesses and they gradually grow into one large shell (see Fig. 1b). The volume of wear products becomes larger than the volume of deteriorated metal. They have limited ability to be removed from the contact area. With time, they cause larger local pressures, acting as abrasive material. Superficial layers of metal, which have been exposed to cyclic deformation for a long time, become so fragile that they loose stability, and their progressive removal begins. This is a reason of wear rate growth. This mechanism of wear correlates with the mechanism presented in [4]. Textured surfaces, in comparison with original specimen, have superrior wear resistance in order of 1,8-2,4. This value depends on design and technological parameters of syrface texture (see Tab. 2). High wear resistance of textured surfaces is due to the fact that dimples play role of "tanks" for wear debris. This helps to remove abrasive particles out of friction contact nd reduce their impact on material.

Proposed mechanism of textured surfaces wear, in contrast to others, takes into account the possibility of removing wear debris from tribo-contact zone into dimples, preventing their abrasive action (Fig. 2).

At the initial stage of textured surface wear process (Fig. 2a), as a result of surface layer elastic and plastic deformation, (in contrast with untreated surface), boundary lubricating films destruct in places of actual frictioncontact between dimples. Also, the juvenile surfaces apeear and seize (microwelding process) As a result of this, primary wear products are formed. Oxygen is adsorbed by juvenile surfaces and oxide films are formed. In sub-surface layers fatigue micro damage accumules. The volume of wear products is gradually increasing, but they may be romoved from friction contact into dimples [24], preventing abrasive damage of the surface (Fig. 2b). In addition dimples reduce accumulatio $n$ of stresses in surface material, thus ensuring relaxation in the areas of actual contact (in the interstices between dimples) space, as well as retaining lubricant in the contact and regeneration of lubricant film. The efficiency of lubricant during wear in fretting conditions is defined by duration of latent period, during which the layer of lubricating maintains protective properties. The duration of the latent period is defined by number of fretting cycles from beginning of friction to a moment of lubricating film destruction. With a sufficiently high metal hardness and other identical conditions (lubricant properties, load, amplitude and frequency of oscillations), the latent period may be expanded due to formation of optimal texture on friction surface (depth and surface density of dimples).

Over the time, during wear, the depth of dimples gradually decreases. This leads to loss of its ability to perform accumulate wear debris from friction surface. During this period surface layer of material, which was exposed to cyclic

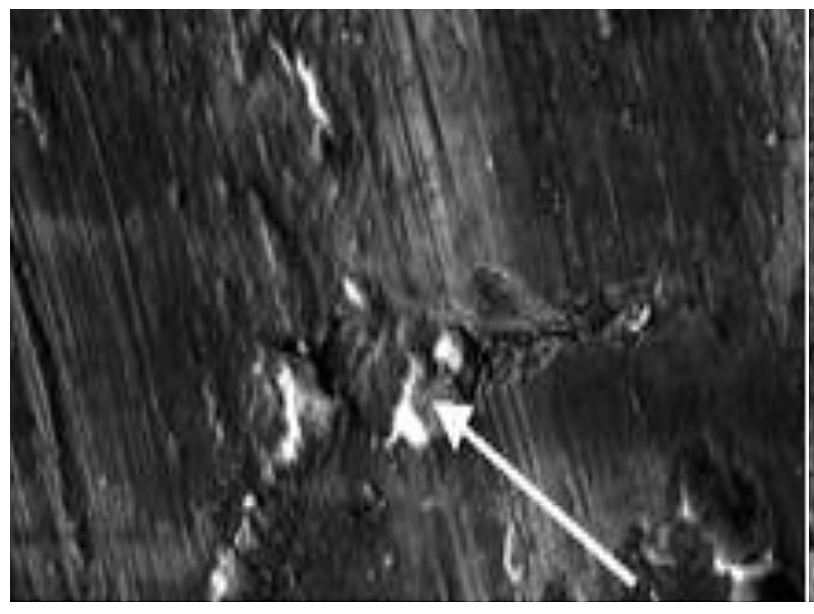

$a$

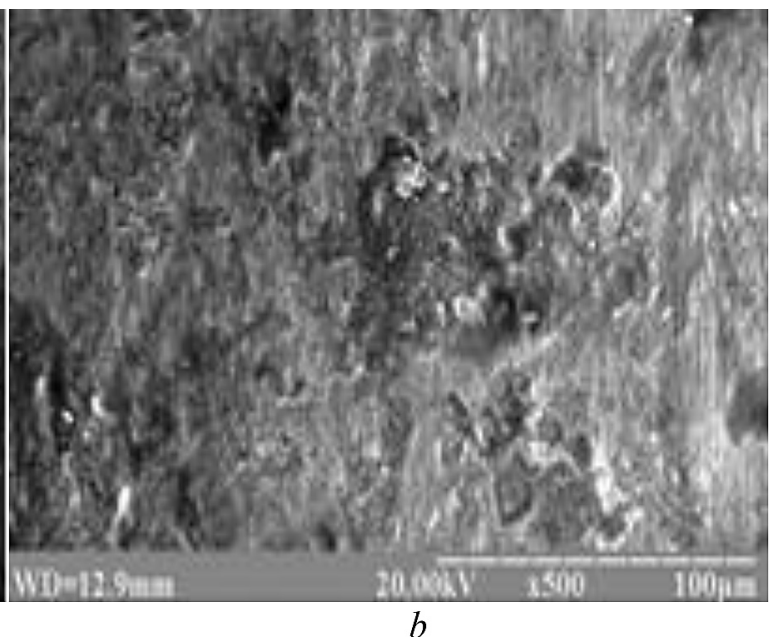

$b$

Fig. 1. Micrographs of worn surface of original (not texture) surface: $a$ - microcrack with impressed wear particle (showed by arrow); $b-$ a shell formed after merging of neighboring recesses 
deformations for a long time starts to destruct fastly. This is perceived in increment of wear rate. High wear rates can lead to rapid increase of temperature due to action of abrasive particles, gradual wearing of dimples. Instead of them, places where wear products become sintered may appear (Fig. 2c). That is, we can assume that, according to the Charpy rule, textured surface will be transformed from a hard matrix and a soft dimple material into a hard dimple and a soft matrix material.

Removal of wear products from tribo-contact into dimples allows to reduce the duration of running-in at fretting conditions. This ia particularly important for responsible and heavy loaded tribo-couples, operating in conditions of lubricant starvation. This is provided by required structural parameters of textured surface. Change of surface geometry $[4,9,25]$ differently influences tribotechnical characteristics, duration of runningin and duration of latent period.

The process of running-in of friction couple can be traced by change of coefficient of friction. Experimental studies of textured surfaces friction coefficient change on the number of cycles during fretting-wear are presented in Figure 3. The analysis showed that change of friction coefficient during the test is nonmonotonic and depends on formed surface texture. At the first load cycles, friction coefficient increases sharply, passes through the maximum, and then with increasing number of load cycles, falls down and then remains nearly constant.

The comparative estimation of change in values of friction coefficients with increase in number of load cycles has allowed to distinguish three characteristic stages of running-in of contiguous surfaces in conditions of fretting-wear. The first stage is characterized by maximum values of friction coefficient. For all surfaces this period is characterized by a short-term rapid increase in friction coefficient during the first load cycles and further sharp decrease.

The largest increase of friction coefficient -0.47 is observed on untextured original surface. This is due to the fact that lubricant film in places of tribo-contact is not integral. Also, prevailing abrasive wear facilitates increase of friction coefficient. Wear products in the interface of tribo-couple lead to intensification of
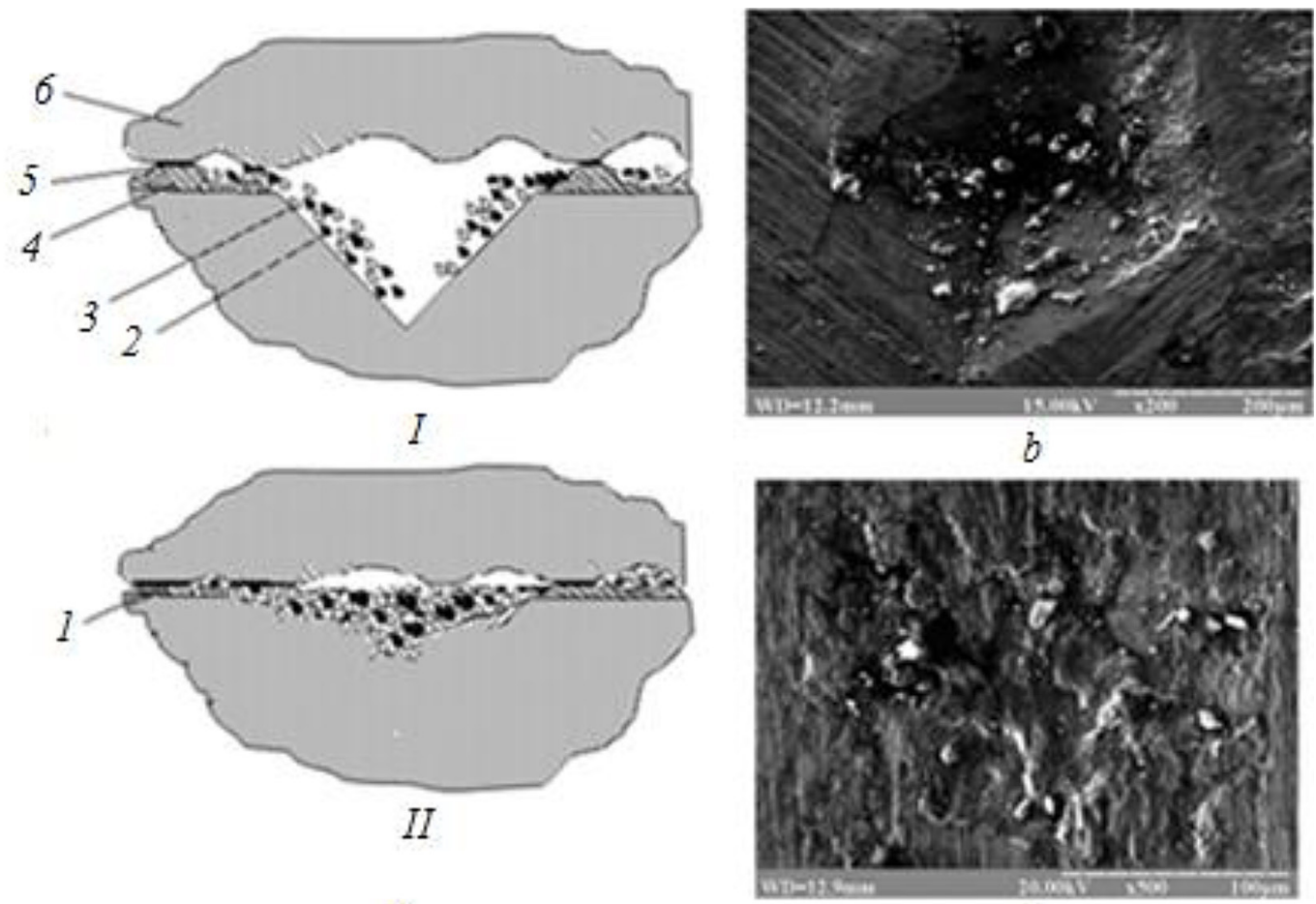

c

Fig. 2. Fretting-wear mechanism of dimpled surface: $a$ - model of dimple wear; $b$ - micrograph of friction surface of individual dimple; $c$ - dimple's surface after smearing; $I$ - stage of strengthening of surface layers and removal of wear products; $I I$ - stage of corrosion-fatigue deterioration of textured surface (interstitial space and dimple); 1 - highly dispersed layer; 2 - metal particles; 3 - oxides; 4 - zone of deteriortion; 5 - boundary lubricating film (zone of actual contact); 6 - coupled surface 


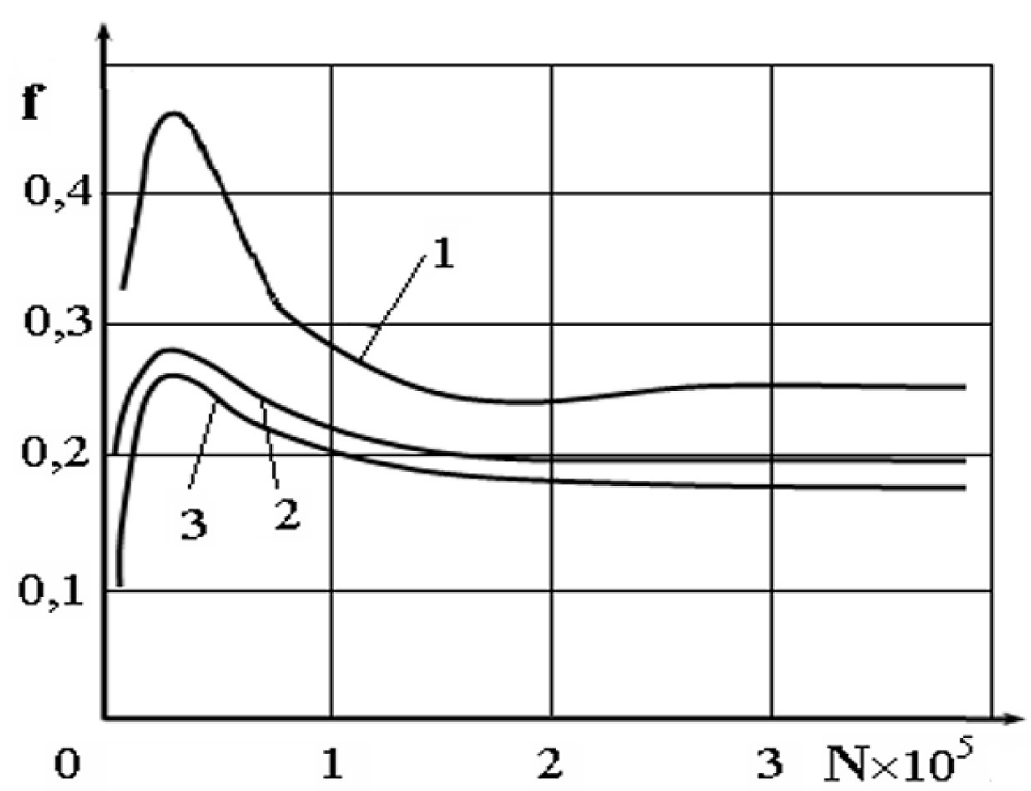

Fig. 3. The dependence of friction coefficient on the number of fretting cycles in conditions of boundary friction: 1 - 30HGSA steel - steel 45; 2 - textured surface No. 1;3 - textured surface No. 2

surface layer abrasive wear, the accumulation of fatigue damage, which leads to increased wear (see Table 2). These processes are associated with local abrasive action of wear products and fatigue «loosening» of metal, enhanced by chemical activation of friction surface.

For textured surfaces this increase of friction coefficient is within the range of $0.25-0.28$ (depending on geometry of textured surfaces), which is $57-62 \%$ less compared to the original untextured surface (see Table 2). In addition, textured surfaces, in comparison with the initial surface, have reduced time of running-in by $10-20 \%$, depending on location dimples and their design parameters. Low values of textured surfaces friction coefficient is associated with the fact that primary wear products are removed into the dimples. This prevents abrasive wear of the surface. The lubricant contained in the dimple ensures regeneration of lubricating film when it is deteriorated and prevents surface damage.

At the second stage of running-in, an improvement in friction may be admitted. The lubricating layer between contacting surfaces is gradually restored, value of friction coefficient decreases less intensively. The difference in values of friction coefficient between the initial surface $(0.27)$ and textured $(0.18-0.2)$ is $66-74 \%$.

The third stage of running-in is characterized by stabilization of friction coefficient, which indicates the normal mechano-chemical wear of the surface and the end of running-in.

\section{CONCLUSIONS.}

1. Running-in process beginning is perceived as rapid increase of friction coefficient, and its end - as its reducing to equilibrium nearly constant value.

2. Maximum friction coefficient for textured surfaces during lubricated friction is $57-62 \%$ lesser then for original untextured material $(0,47$ for untreated and $0,25-0,28$ for textured respectively). At the end of running-in, friction factor is 0,27 for initial surface and $0,18-0,2$ for textured (66-74\% less).

3. Surface texturing in this research provided $10-20 \%$ shorter running-in perion compared to untreaded surface.

4. Hard wear products penetrate wear surface of untextured specimen, this explains so high friction coefficient, while in case of textured surfaces they are washed away into dimples and have minor effect on wear process.

5. Surface wear and fatigue of material around dimples gradualy expands them, reduces their depth. Due to this, the ability to accumulate wear debris reduces, and wear rate is increased.

\section{REFERENCES}

1. Stachowiak G., Podsiadlo P. 3-D Characterization, Optimization, and Classification of Textured Surfaces. Tribology Letters, 2008, 32(1), 13-21. 
2. Pashechko M., Dziedzic K., Barszcz M. Study of the structure and properties of wear-resistant eutectic Fe-Mn-C-B-Si-Ni-Cr coatings. Powder Metallurgy and Metal Ceramics, 2013, 52(7-8), 469-476.

3. Pashechko M., Wear resistance of eutectic coatings of the Fe-Mn-C-B system alloyed with $\mathrm{Si}, \mathrm{Ni}$ and Cr. Materials Science, 2011, 46(5), 695-701.

4. O. Radionenko $\mathrm{O}$, Kindrachuk $\mathrm{M}$, Tisov $\mathrm{O}$, Kryzhanovskyi A. Features of transition modes of friction surfaces with partially regular microrelief. Aviation, 2018, 22(3), 86-92.

5. Dykha A, Dykha M. Increase wearproofness of steel cylindrical details by discrete electromechanical strengthening. IJET, 2018, 7, 6156-6161.

6. Dykha A., Makovkin O., Dykha M. Influence of discrete electromechanical hardening on the wear resistance of steels. Advances in design, simulation and manufacturing II. DSMIE, Springer, 2019.

7. Li X., Li Y., Tong Z., Ma Q, Ni Y., Dong G. Enhanced lubrication effect of gallium-based liquid metal with laser textured surface. Tribology International, 2019, 129, 407-415.

8. F. Meng, H. Yu, C. Gui, L. Chen.: Experimental study of compound texture effect on acoustic performance for lubricated textured surfaces. Tribology International, 2019, Vol. 133, 47-54

9. Kindrachuk M.V., Volchenko O.I., Volchenko D.O., Volchenko N.O., Polyakov P.A., Kornienko A.O., Yurchuk A.O. Polymeric materials modified by semiconductor substances in friction units of braking devices. Journal of nano- and electronic physics, 2019, 11(3), 03014.

10. Chen L., Liu Z., Shen Q. Enhancing tribological performance by anodizing micro-textured surfaces with nano-MoS2 coatings prepared on aluminum-silicon alloys. Tribology International, 122, 84-95.

11. Maharana H. S., Kumar R, Narayana Murty S. V. S., Ramkumar J., Mondal K. Surface micro-texturing of dual phase steel and copper by combining laser machining and electrochemical dissolution. Journal of materials processing technology, 2019, 273,116260 .

12. Lian Y., Deng J., Yao B., Zhuo Y., Lei S. Influence of different cemented carbides on fabricating periodic micro-nano textures by femtosecond laser processing. Surface and Coatings Technology, 2017, 317, 166-171.

13. Yamaguchi K., Takada Y., Tsukuda Y., Ota M., Egashira K., Morita T. Friction characteristics of textured surface created by electrical discharge machining under lubrication. Proc. of 18th CIRP Conference on Electro Physical and Chemical Machining, Tokyo, Japan, 2016, 42, 662-667.
14. Pratap T., Patra K. Fabrication of micro-textured surfaces using ball-end micromilling for wettability enhancement of Ti-6Al-4V. Journal of materials processing technology, 2018, 262, 168-181.

15. Marchuk V., Kindrachuk M., Kryzhanovskyi A. System analysis of the properties of discrete and oriented structure surfaces. Aviation, 2014, 18(4), 161-165.

16. Pashechko M., Kindrachuk M., Radionenko O. The mechanism of friction between surfaces with regular micro grooves under boundary lubrication. Advances in science and technology research journal, 2016, 10(32), 82-85.

17. Gachot C., Rosenkranz A., Hsu S. M., Costa H. L. A critical assessment of surface texturing for friction and wear improvement. Wear, 2017, 372-373, 21-41.

18. Kindrachuk M., Radionenko O., Kryzhanovskyi A., Marchuk V. The friction mechanism between surfaces with regular micro grooves under boundary lubrication. Aviation, 2014, 18(2), 64-71.

19. Golego N.L., Aliabiev F.Ja., Shevelia V.V.: Fretting-corrosion of metals. Technika, 1974.

20. Kindrachuk V. M., Galanov B.A. An efficient approach for numerical treatment of some inequalities in solid mechanics on examples of KuhnTucker and Signorini-Fichera conditions. Journal of the mechanics and physics of solids, 2014, 63, 432-450.

21. Kindrachuk V.M., Galanov B.A., Kartuzov V.V., Dub S.N. Refined model of elastic nanoindentation of a half-space by the blunted Berkovich indenter accounting for tangential displacements on the contact surface. Journal of materials science, 2009, 44(10), 2599-2609

22. Vázquez, C. Navarro, J. Domínguez. Analysis of the effect of a textured surface on fretting fatigue. Wear, 2013, 305, 23-35

23. Patent of Ukraine, F01L 1/20, F01L 1/46. Device for forming indentation relief on the friction surface, which retains lubricants. Marchuk D.Ye., Shul'ga I.F., Pliusnin O.Ye., National Academy of Defence of Ukraine, No. 13762; Declared. 24.10.2005; Published. 17.04.2006. Bulletin No. 4.

24. Joshi G. S., Putignano C., Gaudiusoa C., Stark T., Kiedrowski T., Ancona A., Carbone G. Effects of the micro surface texturing in lubricated nonconformal point contacts. Tribology International, 2018, 127, 296-301

25. Kindrachuk M., Shevchenko A., Kryzhanovskyi A. Improvement of the quality of TiC-Co system plasma coating by laser treatment. Aviation, 2016, 20(4), 155-159. 